JEEP 2011, 00004 (2011)

DOI: $10.1051 /$ jeep/201100004

(C) Owned by the authors, published by EDP Sciences, 2011

\title{
Study of the thermal behavior of syndiotactic and atactic polystyrene by Raman spectroscopy
}

\author{
N. Brun ${ }^{1,2}$, P. Bourson ${ }^{1}$, S. Margueron ${ }^{1}$, M. Duc ${ }^{3}$ \\ ${ }^{1}$ Laboratoire Matériaux Optiques Photonique et Systèmes, SUPELEC, 2 rue Edouard Belin, 57070 Metz, France. \\ 2 Total Petrochemicals France, Usine de Carling, BP 90290, 57508 St Avold.France. \\ ${ }^{3}$ Total Petrochemiclas France, Zone Industrielle Feluy, B-7181 Seneffe Belgium.
}

\begin{abstract}
The glass properties and semi crystalline properties of polymers are observable by X-ray diffraction. Some previous works ${ }^{1,2,3}$ were about determination of degree of crystallinity of sPS by various technologies, like for example DSC, XRD and Raman spectroscopy. The purpose of this paper is to show importance of Raman spectroscopy as analytical tool for the study of amorphous and semi-crystalline phase. The polymers on which our research is achieved, is amorphous polystyrene, shortened aPS, and semi crystalline polystyrene, sPS.
\end{abstract}

\section{Introduction}

A polymer is characterized by one or many phase transitions, as glass transition, crystallization or melting point. Each transition has characteristic temperature, which can be defined by vibrational spectroscopy, differential scanning calorimetry and so on. On other hand, the glass properties and semi crystalline properties of polymers are observable by X-ray diffraction. Some previous works were about determination of degree of crystallinity of sPS by DSC, XRD and Raman spectroscopy.

A lot of properties electrical, chemical, optical or physical can be explained by the chemical structure of polymer. For example, atactic polystyrene and syndiotactic polystyrene present differences about the regularity of their hydrocarbon chain. If the first has phenyl groups randomly distributed on both sides of the chain, the second has got a regular arrangement which the group has alternate positions along the chain. The amorphous or semi-crystalline character depends on reaction of polymerization. Actually, if reaction of polymerization is a radical polymerization, polymer will be amorphous. Whereas, polystyrene made by ZieglerNatta polymerization is semi crystalline.

We propose to use Raman spectroscopy to characterize the crystallinity of polystyrene, in particular, amorphous and semi-crystalline phase. Usual method like
DSC and XRD will experimented to compare the data obtained with Raman spectroscopy.

\section{Backgrounds}

In the study of polymer, it is more important to measure of the glass transition temperature, $\mathrm{T}_{\mathrm{g}}$, and melting temperature $\mathrm{T}_{\mathrm{m}}$. Also, between the glass transition and the melting point, part of the hydrocarbon chain has enough energy to fall into crystalline arrangements. The temperature allowing this crystallisation phenomen is noted $\mathrm{T}_{\mathrm{c}}$. So, the polymer behaviour is fonction of the temperature of treatment. The Figure 1 show behaviour of semi-crystalline polymer, with first field which correponds to glass transition, the second to rubber transtion and the last one is the melt field:

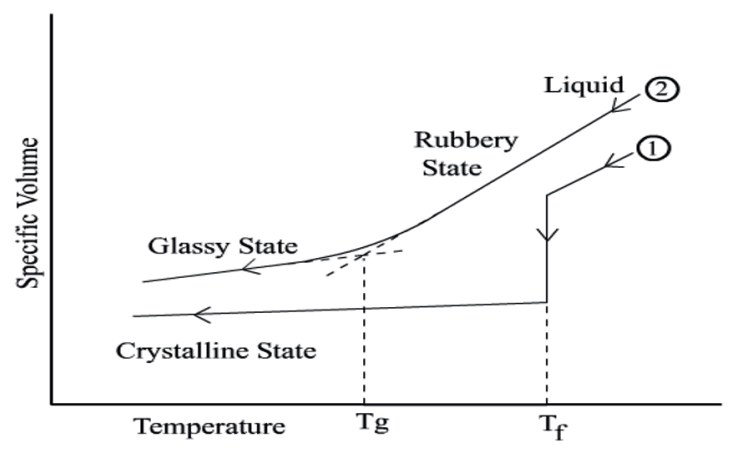

Fig. 1. State diagram of a semi-crystalline polymer 
Furthermore, the literature of syndiotactic polystyrene index four polymorphs, $\alpha, \beta, \gamma$ et $\delta$, can be grouped by pairs, according to the backbone conformation, the $(\alpha, \beta)$ has a planar all-trans "zigzag" conformation whereas the other pair $(\gamma, \delta)$ have a helical trans-trans, gauche-gauche conformation ${ }^{4}$ Figure $2{ }^{5}$, illustrate the two types of conformation that literature gives:
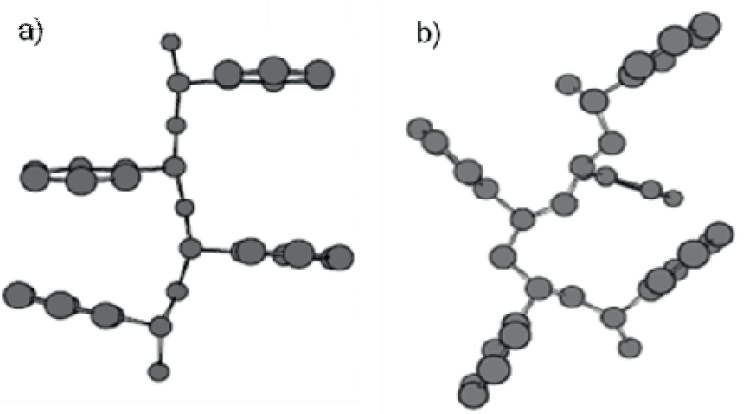

Fig. 2. a) in the $\alpha$ and the $\beta$ forms viewed along an axis perpendicular to the chain axis; b) in the $\gamma$ and the $\delta$ forms viewed along axis perpendicular to the chain axis

This paper present data observed of different transition phase and crystallinity rate. The purpose is to establish a correlation between Raman spectroscopy, DSC and XRD.

\section{Experimental methods}

\subsection{Differential Scanning Calorimetry (DSC)}

The sample weight was approximately $15 \mathrm{mg}$. Only one scan rate was selected, $10{ }^{\circ} \mathrm{C} / \mathrm{min}$ to assess the effect of recrystallization within the material during the scan (20$300{ }^{\circ} \mathrm{C}$ ). The cooling is assured by $\mathrm{N}_{2}$ gaz. In semicrystalline polymers, DSC gives glass temperature, crystallization and melting point. Furthermore, the crystalline rate can be estimated by DSC using enthalpy.

\subsection{X-Ray Diffraction (XRD)}

Usual X-Ray Diffraction equipment is used for this experiment, in order to determine cristallinity rate. The range of measurement extends from 10 to 30 degrees. The revolution speed is $1 \mathrm{rps}$. Experiments of DSC and XRD are made at institute of technology department of "Génie des Matériaux" in Forbach.

\subsection{Laser Raman spectroscopy}

Raman spectra were taken with $785 \mathrm{~nm}$ line of a diode laser. Working at $785 \mathrm{~nm}$ eliminate fluorescent phenomenon important in polymers. This equipment is coupled with a microscope, and a 50x objective is used. The temperature can be adjusted between 30 and $300{ }^{\circ} \mathrm{C}$ in thermostat oven as shown in Figure $3^{6}$. All measurements were umpolarized.

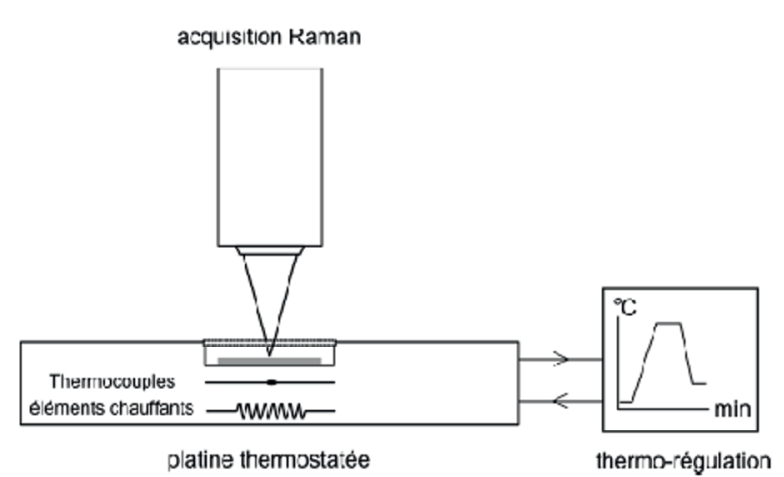

Fig. 3. Thermostat oven with micro Raman Spectroscopy

\section{Results and discussion}

\subsection{Differential Scanning Calorimetry (DSC)}

The first experiment was realized on an atactic polystyrene and a syndiotactic polystyrene. Only one temperature, corresponding to the glass transition is observed. On the second material, three transitions are observed (figure 4), and indexed in the table 1. The first temperature is at $100{ }^{\circ} \mathrm{C}$, and corresponds to the glass temperature. The second is an exothermic peak and correspond to the rubber field, and the last transition is viscous state.

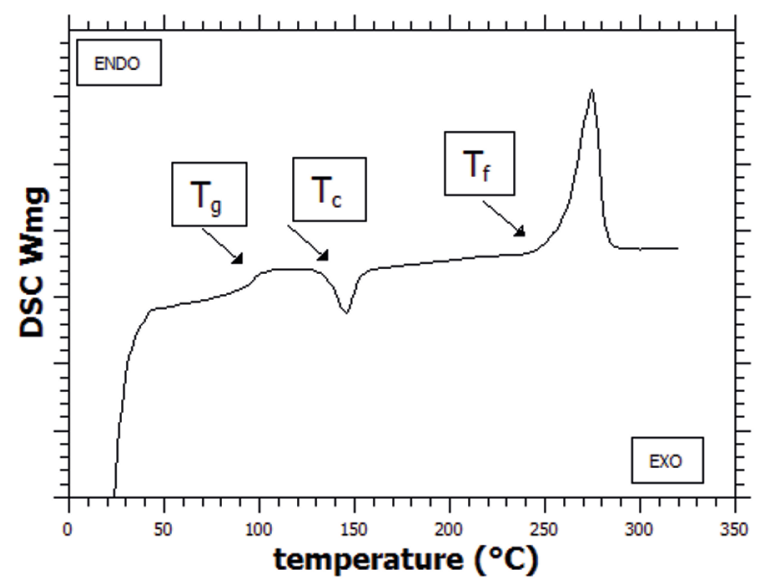

Fig. 4. DSC of sPS material. Arrows show the three different phase transitions in this polymer

Table 1. DSC data obtained for aPS and sPS polymers

\begin{tabular}{|c|c|c|c|c|c|}
\hline & $\begin{array}{c}\mathrm{Tg} \\
\left({ }^{\circ} \mathrm{C}\right)^{2}\end{array}$ & $\begin{array}{c}\mathrm{Tc} \\
\left({ }^{\circ} \mathrm{C}\right)\end{array}$ & $\begin{array}{c}\Delta \mathrm{Hc} \\
(\mathrm{J} / \mathrm{K})\end{array}$ & $\begin{array}{c}\mathrm{Tm} \\
\left({ }^{\circ} \mathrm{C}\right)\end{array}$ & $\begin{array}{c}\Delta \mathrm{Hm} \\
(\mathrm{J} / \mathrm{K})\end{array}$ \\
\hline $\mathrm{aPS}$ & 96 & - & - & - & - \\
\hline sPS & 100 & 146 & 5 & 275 & 22 \\
\hline
\end{tabular}

Using a theoretical enthalpy of $100 \%$ crystalline syndiotactic polystyrene equal to $82,6 \mathrm{~J} / \mathrm{K}^{7}$, we can deduce the crystallinity of our material 


\subsection{X-Ray Diffraction (XRD)}

Seok-Ho Hwang et al. ${ }^{8}$ work about mechanical properties of sPS pure and sPS mixed poly(p-phenylene sulfide), they identified various peaks corresponding to crystallite $\alpha$, and other for crystallite $\beta$, like shown in Figure 7.

Typical X-Ray diffraction peaks of crystallite $\alpha$ are obtained at $2 \theta=6.62^{\circ}, 11.63^{\circ}, 13.44^{\circ}, 15.6^{\circ}$ and $18^{\circ}$. In the same way, the crystallite $\beta$ is characterized by the peaks at $2 \theta=6.1^{\circ}, 12.3^{\circ}, 18.6^{\circ}$ and $20.28^{\circ}$.

On XRD measurements, Figure 5, the same peaks are observed, but there is one more at $29.31^{\circ}$. However, for $15<2 \theta<25$, graph is a little bit ambiguity, because this experiment is made on pellets of syndiotactic polystyrene.

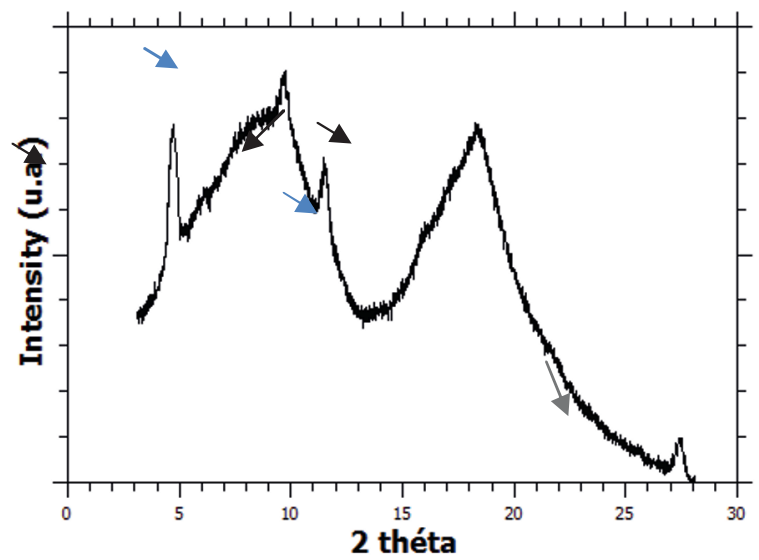

Fig. 5. X-ray diffraction of sPS. Bllue arrows indicate different crystallite $\alpha$ and balck arrows correspond crystallite $\beta$. Grey arrow indicate one more peak

The XRD of a PS has no peaks as expected in an amorphous polymer.

\subsection{Laser Raman spectroscopy}

\subsubsection{Preliminary work}

Raman spectra of atactic polystyrene and syndiotactic polystyrene were investigated, in order to determine signature of crystallinity.

The Raman spectrum of atactic polystyrene shows peaks which are different compared to Raman spectrum of syndiotactic polystyrene, as shows in figure 6 .

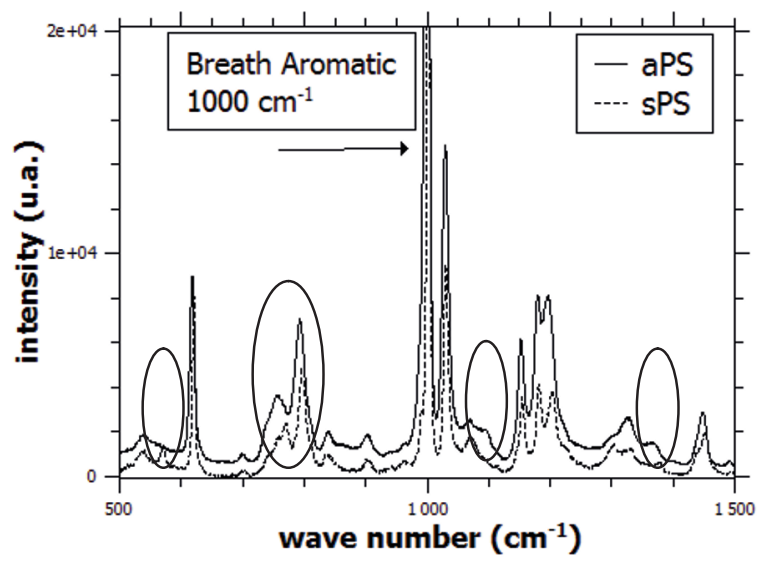

Fig. 6. Raman spectrum of aPS (black) and sPS (dash line). Circles show the main differences between aPS and sPS spectra

At first sight, differences are observed at $575 \mathrm{~cm}^{-1}$ with a supplementary peak for sPS. The field $700-800 \mathrm{~cm}^{-1}$ is really different, as around $1100 \mathrm{~cm}^{-1}$, and beyond $1300 \mathrm{~cm}^{-1}$.

Using Raman spectroscopy, Kobayashi et al ${ }^{9}$ observed that the $v_{1}$ vibration is very sensitive to the local backbone conformation resulting in the presence of two distinct peaks at 770-773 and 796-802 $\mathrm{cm}^{-1}$ corresponding to all-ltrans conformations and mixed trans/gauche conformations, respectively.

In Figure 7, the part of Raman spectrum of sPS is given and shows peak position, of all-trans and transgauche.

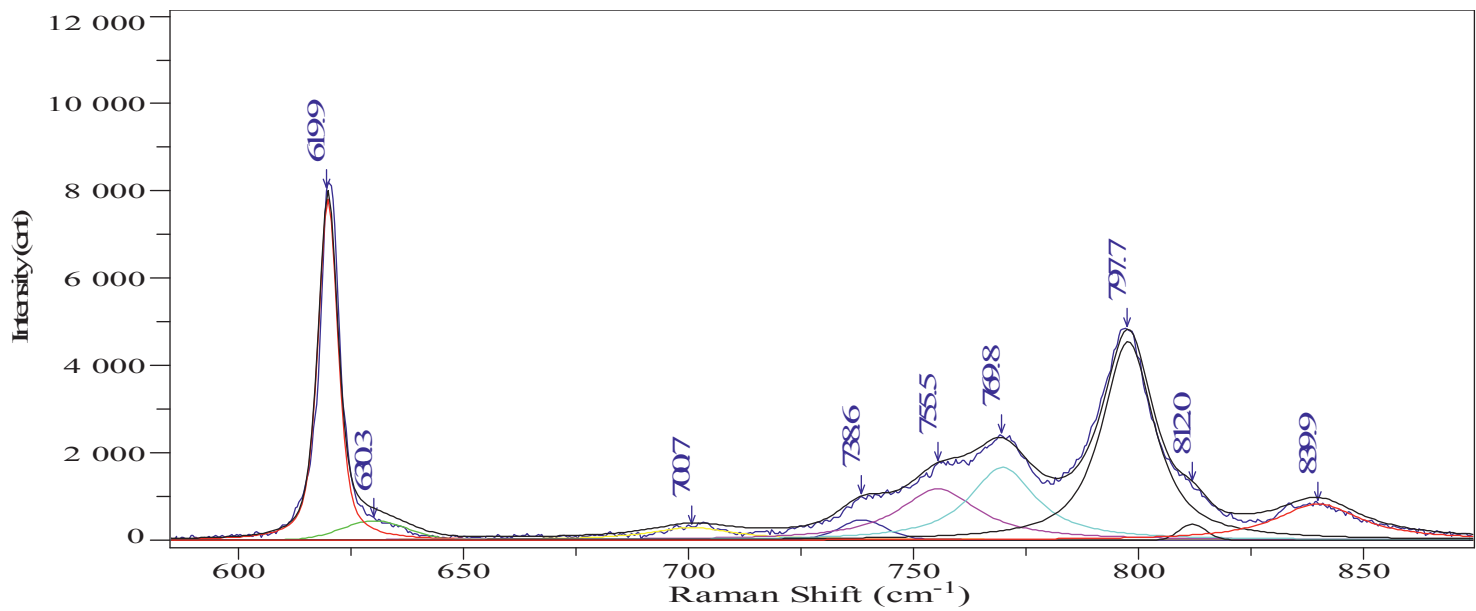

Fig. 7. Fitted Raman spectrum of sPS, from 600 to $850 \mathrm{~cm}^{-1}$ at room temperature 


\subsubsection{Crystallization temperature}

In Figure 8, we focus on the spectra part from 700 to 800 $\mathrm{cm}^{-1}$. The peak observed at $770 \mathrm{~cm}^{-1}$, which is relating all-trans conformation, increases with temperature. Whereas the peak at $797 \mathrm{~cm}^{-1}$, which is associated transgauche conformation, reduces with temperature:

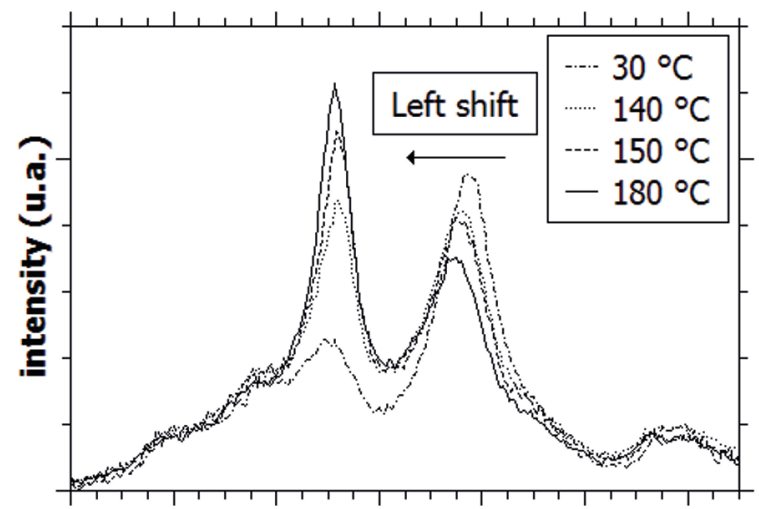

shift raman $\left(\mathrm{cm}^{-1}\right)$

Fig. 8. Raman spectrum of sPS at $30^{\circ} \mathrm{C}, 140{ }^{\circ} \mathrm{C}$, $150{ }^{\circ} \mathrm{C}$, and $170^{\circ} \mathrm{C}$

Moreover, we observe a shift of the band at $796 \mathrm{~cm}^{-1}$ towards the low frequencies, corresponding to a compression of the liaison. The evolution of these peaks can be made in equation by the relation (1) and (2), which is a ratio of area. Results are represented on Figure 9.

$$
\mathrm{R}_{\text {all-trans }}=\frac{\mathrm{A} 770}{A 770+A 797}
$$

and

$$
\mathrm{R}_{\text {trans-gauche }}=\frac{\mathrm{A} 797}{A 770+A 797}
$$

We define the peak at $770 \mathrm{~cm}^{-1}$, as corresponding to all-trans conformation. And the other peak characterizes trans-gauche conformation. So, we can approximate proportion of each conformation in function of the temperature. We observe an intersection between the two equations at $149^{\circ} \mathrm{C}$, which is exactly the temperature of crystallization, given by DSC. On other hand, the change of slope for the both equation begins at $120{ }^{\circ} \mathrm{C}$. This temperature is related to the end of vitreous part.

Consequently, below crystallize temperature, transgauche conformation is prevailing, whereas beyond $T_{c}$, allgauche conformation is predominant. In addition, proportion established by equation (1) and (2), is constant in function of the temperature.

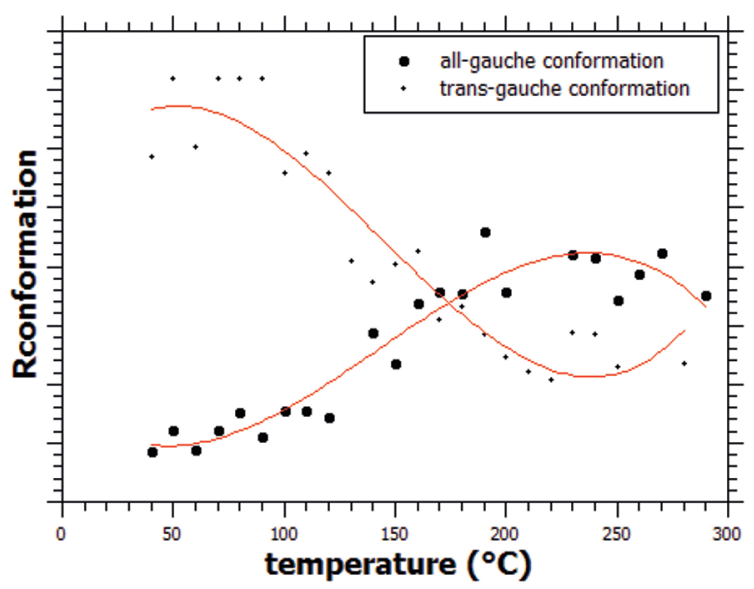

Fig. 9. Proportion of $R_{\text {all-trans }}$ and $R_{\text {trans-gauche, }}$ as a function of temperature

\subsubsection{Phase transitions}

Five peaks on Raman spectra are interesting for study of the phase transitions, in particular that at $235 \mathrm{~cm}^{-1}$.

Normalized with the peak at $1000 \mathrm{~cm}^{-1}$, independent of the temperature, give equation (3):

$$
\mathrm{R}_{235}=\frac{\mathrm{A} 235}{A 1000}
$$

On Figure 10, we observe a linear ratio for temperature from $40{ }^{\circ} \mathrm{C}$ to $120^{\circ} \mathrm{C}$. After, a maximum is observed at approximately $135{ }^{\circ} \mathrm{C}$. This temperature corresponds approximately to the crystallization temperature. Then, some intensity is observed without attribution. And finally, another maximum is observed at $270{ }^{\circ} \mathrm{C}$, which is exactly the same temperature as melting temperature found in DSC.

Consequently, we define three temperature ranges, one from ambient temperature to $120{ }^{\circ} \mathrm{C}$, equivalent the vitreous phase, and another field from $270{ }^{\circ} \mathrm{C}$, matching the viscous phase. And between the two, we observe a rubber field. We confirm the results as the literature observations, with the three phase transition (Figure 1).

These observations are confirmed by the same type of ratio, $\left(R_{i}=A_{i} / A_{1000}\right)$, with the peak at $525 \mathrm{~cm}^{-1}$, which appear only from $120^{\circ} \mathrm{C}$, and with peak at $1316 \mathrm{~cm}^{-1}$. 


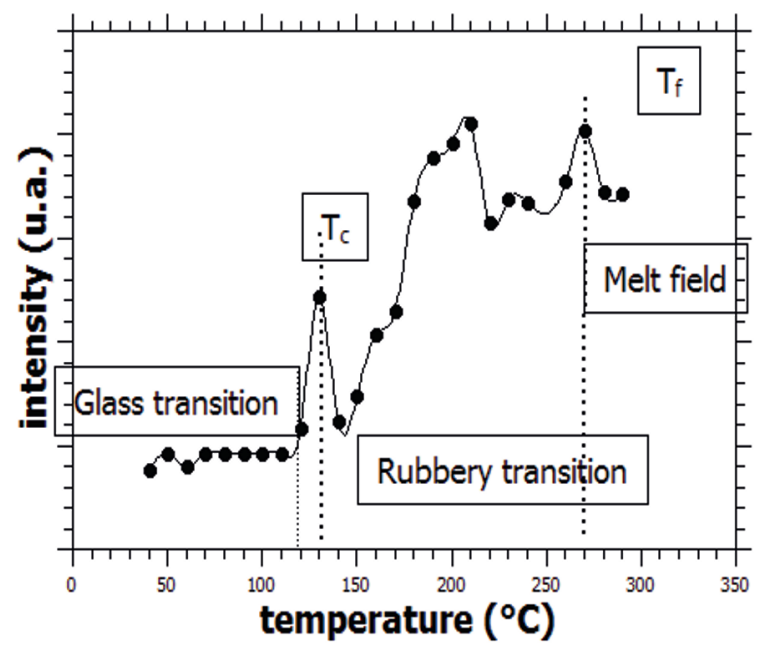

Fig. 10. Evolution of the $235 \mathrm{~cm}^{-1}$ peak, normalized to the peak at $1000 \mathrm{~cm}^{-1}$ with temperature.

\subsubsection{Cristallinity rate}

DSC and XRD give the crystallinity rate, we would like to establish a relationship between this property and Raman spectroscopy. So, we compare the three values obtained by the three different methods.

In DSC, we use theoretical enthalpy to estimate the cristallinity of polystyrene. In XRD, peaks are the consequence of presence crystalline phase. In Raman spectroscopy, we consider the peak at $1316 \mathrm{~cm}^{-1}$.

On account of, it is maximal for $275^{\circ} \mathrm{C}$, at melting point, dividing the value at ambient temperature by this value, equation (4), we can approach $\chi_{c}$ :

$$
\chi_{\mathrm{c}}=\left(\operatorname{Rc} 30^{\circ} \mathrm{C} / \operatorname{Rc} 275^{\circ} \mathrm{C}\right) * 100
$$

with

$$
\mathrm{R}_{\mathrm{c}}=\mathrm{A}_{1316 / \mathrm{A}_{1000}}
$$

So, the crystallinity is indexed in table 2 :

Table 2. Crystallinity rate estimated by DSC, XRD and Raman spectroscopy

\begin{tabular}{|l|l|l|}
\hline DSC DSC & DRX & $\begin{array}{l}\text { Raman } \\
\text { Spectroscopy }\end{array}$ \\
\hline $4,1 \%$ & $6 \%$ & $4,3 \%$ \\
\hline
\end{tabular}

Current investigation is undergoing to obtain different crystallinity ration.

\section{Conclusion}

In this work, a comparison of Raman spectra of amorphous polystyrene and semi-crystalline polystyrene has been investigated.
Raman bands in the 700 to $800 \mathrm{~cm}^{-1}$ present peak sensitive to the crystallinity and the conformation. The study in function of temperature allows determining the state diagram of syndiotactic polystyrene. In particular, peaks at 770 and $797 \mathrm{~cm}^{-1}$ give the crystallization temperature, similarly, the all-trans and trans-gauche conformation have each one a prevalence field according to our work the temperature.

Moreover, the evolution of the three peaks, those at 235, 525 and $1316 \mathrm{~cm}^{-1}$ give phase transition, glass, rubber and viscous field. The state diagram of semicrystalline polymer is known by literature, and data obtained by Raman spectroscopy can establish it and can be correlated with DSC and XRD. On other hand, we estimate crystallinity ratio. Investigation is currently done to obtain various crystallinity ratio by annealing in order to confirm our hypothesis.

\section{Acknowledgements}

The authors wish to thank the teams of Total Petrochemicals France who made the sampling of polystyrene and supplied the information useful for this study as well as the staff of the University Institute of Technology of Forbach for their contribution and equipment necessary for the study.

\section{References}

1. Kellar E. J. C., Galiotis C., Andrews E. H., 1996 Raman Vibrational Studies of Syndiotactic Polystyrene. 2. Use of the Fundamental 11 Vibrational Mode as a Quantitative Measure of Crystallinity within Isotropic MaterialMacromolecules 24, 3662

2. Jasse, B.; Chao, R. S.; Koenig, J. L. J. Raman Spectrosc. 1979, 8, 244.

3. Guerra, G.; Vitagliano, V. M.; De Rosa, C.; Petraccone, V.;Corradini, P. Macromolecules 1990, 23, 1539.

4. Corradini, P.; Guerra, G. Adv. Polym. Sci. 1992, 100, 183.

5. Elena Trezza, thesis Dynamical Behaviour of Small Molecules Clathrated in Syndiotactic Polystyrene, a Solid State Deuterium NMR Investigation 2003.

6. Julien Martin thesis Etude par spectroscopie Raman du polypropylène isotactique au cours de sa déformation uniaxiale

7. Gianotti, G.; Valvasaori, A, Polymer 1990, 31, 473.

8. Seok-Ho Hwang, Myeong-Jun Kim, Jae-Chang Jung Mechanical and thermal properties of syndiotactic polystyrene blends with poly(p-phenylene sulfide) European Polymer Journal 38 (2002) 1881-1885

9. Kobayashi, M.; Nakaoki, T.; Ishihara, N. Macromolecules 1989, 22, 4377 